\title{
Determining whether attentional control settings are inclusive or exclusive
}

\author{
JAY PRATT \\ University of Toronto, Toronto, Ontario, Canada \\ and \\ JIM MCAULIFFE \\ Lakehead University, Thunder Bay, Ontario, Canada
}

\begin{abstract}
The aim of the present study was to determine whether attentional control settings operate with an inclusive rule (orient attention to stimuli that share a task-relevant feature with the target) or an exclusive rule (do not orient attention to stimuli that do not share a task-relevant feature with the target). All three experiments used a variation of the Folk and Remington (e.g., Folk, Remington, \& Johnston, 1992) paradigm. In Experiment 1, cuing effects were found for combination cues (cues containing an onset feature and a color feature) with both onset and color targets. Experiment 2, using a delay between cue and target, revealed inhibition of return (IOR) for combination cues with onset and color targets. Unexpectedly, IOR was also found for onset cues with color targets, and this finding was confirmed in Experiment 3. These findings indicate that attentional control settings use an inclusive rule. Moreover, the presence of IOR with onset cues and color targets suggests that onset cues may automatically capture attention, but attention control settings allow for rapid disengagement when the onset cue does not contain a task-relevant feature.
\end{abstract}

Attentional capture refers to the notion that some salient aspect of a peripheral stimulus will reflexively cause visual attention to be oriented to that stimulus. Initially, attentional capture was thought to be due to an abrupt change in luminance at a peripheral location (e.g., Yantis \& Jonides, 1984, 1990). Later research indicated that the appearance of new objects may be the critical element in attentional capture (Yantis \& Hillstrom, 1994) or that any salient stimulus difference may be sufficient to capture attention (e.g., Theeuwes, 1992, 1994). These findings pointed to the role of stimulus-driven processing in attentional capture; under such circumstances, the allocation of attention was under the control of the stimulus.

However, an extensive program of research undertaken by Folk and Remington (Folk \& Remington, 1998; Folk, Remington, \& Johnston, 1992; Folk, Remington, \& Wright, 1994; Remington, Folk, \& McLean, 2001) has provided strong evidence for the role of goal-directed processing in attentional capture. The major finding produced by this body of research is that salient peripheral events (the appearance of a new object, a luminance transient, a color transient) do not result in the capture of attention. Rather, attentional capture occurs only when the peripheral event shares a critical feature with the target stimulus. Their basic paradigm uses a display consisting

This research was supported by a Natural Sciences and Engineering Research Council of Canada award to J.P. Correspondence should be addressed to J. Pratt, Department of Psychology, 100 St. George Street, University of Toronto, Toronto, ON M5S 3G3, Canada (e-mail: pratt@psych.utoronto.ca). of four peripheral boxes arranged around a central fixation box. The task is to determine the identity of either a red target stimulus presented with white distracting stimuli at the other three locations (color target) or a white target stimulus presented without distractors (onset target). Just before the appearance of the targets, one of two types of cues (to which no response is required) is presented. Color cues consist of four red dots around one of the peripheral boxes and three sets of four white dots around the other peripheral boxes, whereas onset cues consist of only four white dots around one of the peripheral boxes. Folk and Remington have consistently found that attentional capture (indicated by faster reaction times [RTs] to targets at the validly cued locations than at the invalidly cued locations) occurs only when the color cues are paired with color targets and the onset cues are paired with onset targets. Likewise, they have also consistently found that attentional capture does not occur when the cues and targets are mismatched. Using variations of the Folk and Remington contingent capture paradigm, several studies have reported similar findings (e.g., Gibson \& Amelio, 2000; Pratt, Sekuler, \& McAuliffe, 2001).

Folk and Remington interpreted their findings as evidence for the effect of a goal-directed attentional control setting mediating attentional capture (e.g., Folk et al., 1992; Folk et al., 1994). Thus, Folk and Remington suggest that attentional capture is not strictly a stimulusdriven process, but rather that attentional capture can be influenced by the requirements of the task. The basic notion is that top-down processes use the task-relevant feature information to produce an attentional set. Attention 
will then be captured by any stimulus that contains the task-relevant feature, even if that particular stimulus is a cue that does not require a response. Folk and Remington have termed this type of attentional capture contingent involuntary orienting, indicating that the involuntary capture of attention is contingent on the stimulus having a feature that is consistent with the behavioral goal (e.g., Remington et al., 2001).

The aim of the present study was to determine how the attentional control settings operate. As conceived by Folk and Remington (e.g., Folk et al., 1992; Folk et al., 1994; Remington et al., 2001), the attentional control settings limit the orienting of attention to peripheral stimuli that have a task-relevant feature. For example, in a typical Folk and Remington paradigm, a person may be instructed to identify the red target (a red stimulus appearing in one peripheral location and white distractor stimuli appearing in the other three peripheral locations). The attention control setting might be specified like this: "Allocate attention to anything that is red." Such an attentional control setting could be considered to use an inclusive rule (i.e., the attentional set includes stimuli that have task-relevant features). However, it is also possible that the attentional control setting uses an exclusive rule. In this case, stimuli that contain features other than the task-relevant features might be selected against having attention directed toward them. For an exclusive rule, the attentional control setting might be specified like this: "Do not allocate attention to anything that is white or is a single stimulus onset." Thus, although these rules work in opposite ways, both would produce the pattern of results found with the Folk and Remington paradigm.

Although both inclusive and exclusive rules would result in the same observable attention control setting effects in the Folk and Remington paradigm, there are reasons to believe that control settings are implemented using an inclusive rule. Although typical visual search tasks do not use separate cue and target stimuli, these tasks are similar to the attentional capture tasks in that participants can perform such tasks by either orienting attention toward taskcompatible stimuli (e.g., "knowing the target is red, allocating attention only to the red items") or by selectively ignoring or inhibiting task-incompatible stimuli (e.g., "knowing the target is red, do not allocate attention to the blue items"). Friedman-Hill and Wolfe (1995; Experiment 4) found efficient searches when participants were instructed to find the odd red item (among red and green distractors). However, they found very inefficient searches when the task was to find the odd item among the set of items that were not green (with red, yellow, purple, blue, and green distractors). Because searching for a red item and not searching for a green item reduced the search set by the same amount (each eliminated half of the search set), these results are consistent with a top-down control setting that uses an inclusive rule.

Support for control settings using an inclusive rule can also be found in Folk and Remington (1996). Using a variation of their contingent capture paradigm, they gave participants advance information about the location of the cue and what relationship the cue shared with the target. In the first experiment, they found that peripheral cues captured attention even though participants knew that the target would never appear at the cued location and were told in advance of each trial where the cue would occur. Similar attentional capture effects were also found in the second experiment, in which the cue location was held constant over a block of trials (although in this case the cue was uninformative as to the location of the target). The third experiment showed that cues captured attention even when they occurred at positions at which targets never occurred. Thus, the rule for where attention will be allocated appears to be inclusive (e.g., "orient attention toward a cued location") and not exclusive (e.g., "do not orient attention to nontarget locations").

Despite this earlier research, the question remains whether the attentional control settings, which determine what cues will capture attention and which will not, use an inclusive or exclusive rule. To examine this question, a new type of cue stimulus must be added to the basic Folk and Remington paradigm. This is because in the basic paradigm the two types of cues and the two types of targets do not share any features. In fact, this is true not only of the basic Folk and Remington paradigm (e.g., Folk et al., 1992; Folk et al., 1994), but also all of the numerous variants of the basic paradigm (e.g., Folk \& Remington, 1998; Remington et al., 2001). For all of these experiments, the onset cues and targets consist of white stimuli that are presented at a single peripheral location with no distractors, whereas the color cues and targets consist of red stimuli that are presented at one peripheral location with white distractors at the other peripheral locations. Because of this, the inclusive rule ("when searching for the onset target, allocate attention to anything white or a single onset") or the exclusive rule ("when searching for the red target, do not allocate attention to anything white or a single onset") results in the identical behavioral consequences. However, a cue that shares some features of the onset target and some features of the color target might either be included in the attentional set or be excluded from it. In other words, depending on the rule used by the attentional control setting, such a combination onset/color cue might or might not capture attention. The inclusive/exclusive nature of attentional capture is examined in the first and second experiments of the present study, and the third experiment explores an unexpected result from Experiment 2.

\section{EXPERIMENT 1}

To determine whether attention set is inclusive or exclusive in nature, Folk and Remington's (e.g., Folk et al., 1992; Folk et al., 1994) basic onset and color cue/target stimuli and paradigm were used. In addition, a new cue was used that contained features of both the onset and the color cues. This combination cue consisted of the same four red dots that were used as the color cue, but in this 
case were not presented with the three sets of white distractors. In this way, the combination cue contained a critical feature that would allow it to be included into either attentional control setting (red for color targets, single onset for onset targets) and a critical feature that would allow it to be excluded from either attentional setting (red for onset targets, single onset for color targets). Thus, if the rule is inclusive, cuing effects (faster RTs to targets at the validly cued location) should be found for combination cues with either target type (i.e., the red onset cue would capture attention when participants are searching for either red targets or onset targets). However, if the rule is exclusive, then the combination cues should not produce cuing effects for onset or color targets.

\section{Method}

Participants. Sixteen undergraduate students from the University of Toronto participated in this experiment in return for course credit. Eight participants served in the onset target condition, with the other eight serving in the color target condition.

Apparatus and Procedure. Participants were seated directly in front of a computer monitor and standard QWERTY keyboard. The viewing distance, $44 \mathrm{~cm}$, was held constant by a head/chin rest. The room was dimly lit by an incandescent light source.

The trial sequence was very similar to that used by Folk et al. (1992; see Figure 1). Each trial began with an initial display of a central fixation box and four peripheral boxes (above, below, to the right, and to the left of the fixation box) presented in light gray $\left(5 \mathrm{~cd} / \mathrm{m}^{2}\right.$, IBM Color 8$)$ on a black background $\left(0 \mathrm{~cd} / \mathrm{m}^{2}\right.$, IBM Color 0 ). Each box subtended $1.1^{\circ}$ of visual angle and the peripheral boxes were centered $4.9^{\circ}$ from the center of the fixation box. Five hundred milliseconds later, the center box blinked off for $100 \mathrm{msec}$ and then returned. Then, following a variable foreperiod of $1,000-1,400 \mathrm{msec}$ (in $100-\mathrm{msec}$ increments), a cue was presented for $50 \mathrm{msec}$ and then removed. The cue was an onset cue (four white dots surrounding only one of the peripheral boxes), a color cue (four red dots surrounding one of the peripheral boxes while four white dots surrounded the three other boxes), or a combination cue (four red dots surrounding one of the peripheral boxes with no cues at the other peripheral locations). The white cues were bright white $\left(77 \mathrm{~cd} / \mathrm{m}^{2}\right.$; IBM Color 15$)$ and the color and combination cues were bright red $\left(17 \mathrm{~cd} / \mathrm{m}^{2}\right.$; IBM Color 12$)$; each dot subtended $0.35^{\circ}$. Following a $100-\mathrm{msec}$ delay, the target was presented for $50 \mathrm{msec}$ and then removed. One group of participants (onset target group) received only an onset target (a white "+" or "=" presented in only one of the peripheral boxes). The other participants

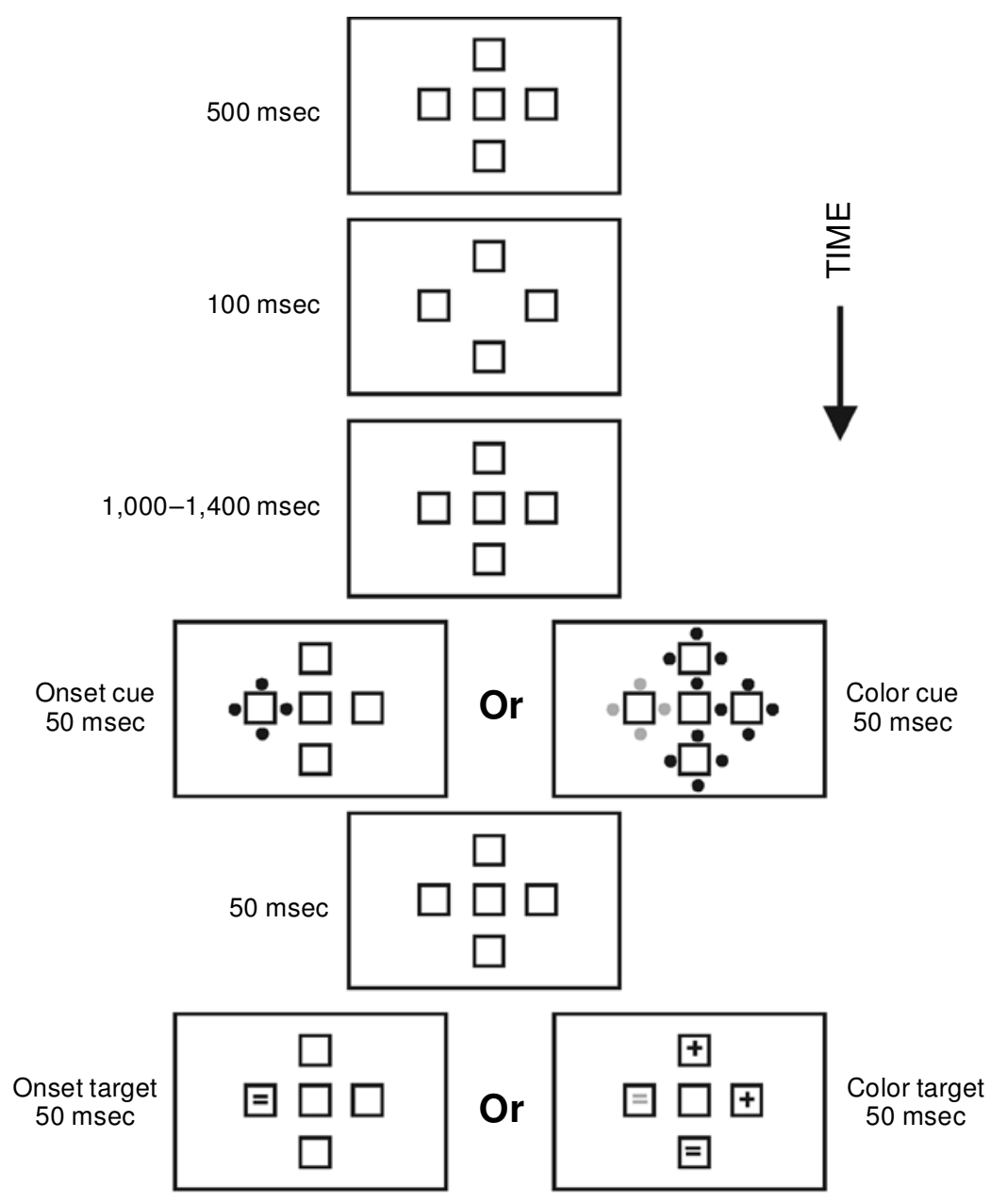

Figure 1. The basic trial sequence used in Experiment 1. Cues and targets were equally likely to occur at any of the four peripheral locations. 
(color target group) received only a color target (a red "+" or "=" presented in one of the peripheral boxes while white "+"s or "="s were presented in the three other boxes). The targets were presented in the same high-contrast white and red as the cues.

The participants were informed that the cue conveyed no information about the location of the target and were instructed to determine the identity of the target as quickly and accurately as possible. They were to press the "Z" key using their left hand if the target was a "+" and the "/" key with their right hand if the target was a " =." If they pressed the wrong key or responded faster than $100 \mathrm{msec}$ or slower than $1,500 \mathrm{msec}$, the response was considered an error and a short tone $(200 \mathrm{~Hz}, 200 \mathrm{msec})$ was presented. Error trials were not included in the RT analyses. The intertrial interval was $500 \mathrm{msec}$ and after every 128 trials a short break was provided.

Design. Each participant completed 384 trials, with 128 trials in each of the three possible cue-target combinations for the onset group (onset-onset, color-onset, and combination-onset) and for the color group (onset-color, color-color, and combination-color). The type of cue and the location of the cues and targets were randomized across each session. Thus, valid trials (target at the same location as the cue) occurred $25 \%$ of the time whereas invalid trials (target at a different location than the cue) occurred $75 \%$ of the time.

\section{Results and Discussion}

The mean RTs from correct trials appear in Figure 2; they were analyzed with a 2 (group: onset target or color target) $\times 3$ (cue: onset, color, or combination) $\times 2$ (trial type: valid or invalid) analysis of variance (ANOVA). There was a main effect of group $\left[F(1,14)=9.2, M S_{\mathrm{e}}=\right.$ $30,836, p<.01$ ], with faster RTs for the onset target group (448 msec) than for the color target group $(556 \mathrm{msec})$. This is not surprising since the color target trials involved distractors whereas the onset target trials did not. A main effect was also found for cue $\left[F(2,28)=4.5, M S_{\mathrm{e}}=419\right.$, $p<.03$ ], with RTs to combination cues $(511 \mathrm{msec})$ slower than onset (499 msec) and color $(497 \mathrm{msec})$ cues. Most important, a main effect for trial type was found $[F(1,14)=$ $82.1, M S_{\mathrm{e}}=363, p<.0001$ ], with RTs on valid trials (484 msec) faster than RTs on invalid trials $(520 \mathrm{msec})$. Thus, overall, there was a cuing effect.

Any differential cuing effects due to specific combinations of cues and targets would be shown in the interactions of cue and group with trial type. This was the case, as significant two-way interactions were found for group $\times$ trial type $\left[F(1,14)=38.7, M S_{\mathrm{e}}=363, p<\right.$ $.0001]$ and for cue $\times$ trial type $\left[F(2,28)=14.2, M S_{\mathrm{e}}=\right.$ $251, p<.0002]$. The group $\times$ cue interaction was very close to being significant $\left[F(2,28)=3.1, M S_{\mathrm{e}}=419\right.$, $p<.06]$. The three-way interaction of group $\times$ cue $\times$ trial type was also found to be significant $[F(2,28)=$ 34.0, $\left.M S_{\mathrm{e}}=251, p<.0001\right]$. To sort out these two- and three-way interactions, the mean cuing effects (invalid RT minus valid RT) were calculated for each cue-target combination, and post hoc tests were conducted to determine which combinations yielded significant cuing effects. As indicated by the asterisks in Figure 2, cuing effects were found for the conditions in which the cue matched the target (onset cue-onset target, color cue-color target) and for the combination cue.

The percentage of errors, shown in Table 1, was analyzed with a 2 (group) $\times 3$ (cue) $\times 2$ (trial type) ANOVA. No main effects or interaction effects were found $(F \mathrm{~s}<$ $2.2, p \mathrm{~s}>.13)$.

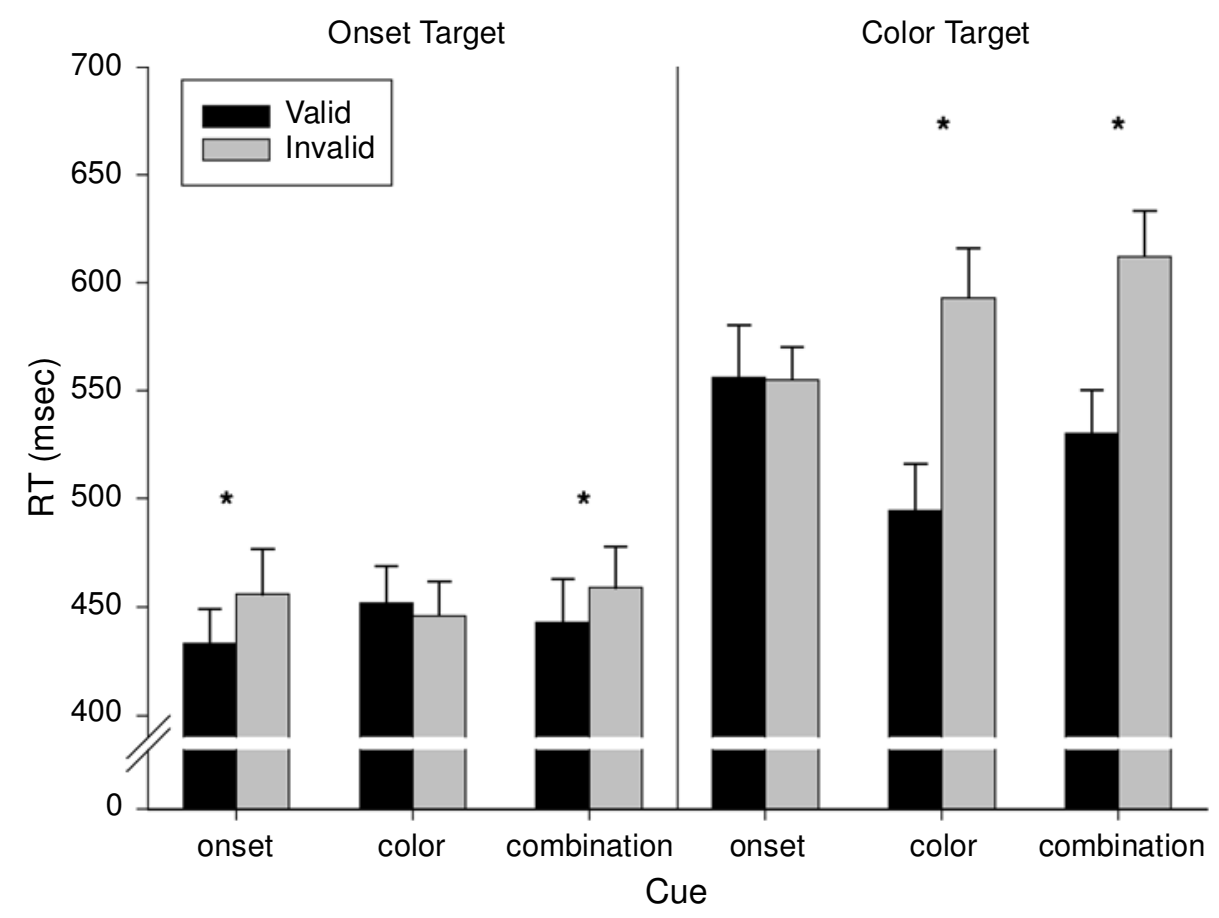

Figure 2. The mean RTs for valid and invalid trials found with the 150-msec SOA used in Experiment 1 . The asterisks indicate significant effects $(p<.05)$, and error bars represent standard error. 
Table 1

Percentage of Errors in Experiments 1 and 2

\begin{tabular}{lccccc}
\hline & \multicolumn{2}{c}{ Experiment 1 } & & \multicolumn{2}{c}{ Experiment 2 } \\
\cline { 2 - 3 } \cline { 5 - 6 } & Valid & Invalid & & Valid & Invalid \\
\hline Onset Target & & & & & \\
$\quad$ Onset cue & 3.8 & 4.8 & & 2.3 & 2.3 \\
$\quad$ Color cue & 5.5 & 4.1 & & 1.5 & 2.1 \\
$\quad$ Combination cue & 4.0 & 3.3 & & 2.4 & 2.5 \\
Color Target & & & & \\
$\quad$ Onset cue & 3.0 & 2.6 & & 6.1 & 4.6 \\
$\quad$ Color cue & 2.6 & 4.5 & & 3.5 & 4.0 \\
$\quad$ Combination cue & 3.4 & 4.8 & & 4.6 & 4.6 \\
\hline
\end{tabular}

To begin with, the results from the typical Folk and Remington onset and color cues were exactly as expected. Cuing effects were found with onset cues paired with onset targets and color cues paired with color targets. The mismatched pairs (onset cues with color targets, color cues with onset targets) failed to show any cuing effects. Thus, there is strong evidence that participants entered into an attentional set depending on what type of target they were asked to respond to. In terms of whether the attentional set is inclusive or exclusive, cuing effects were found for both types of targets with the combination cues. This finding indicates that stimuli are included into the attentional set if they share a feature with the target, rather than being excluded from the attentional set if they contain a an irrelevant feature. In other words, the results indicate that red onset cues will capture attention when people are searching for either red targets or onset targets.

\section{EXPERIMENT 2}

The first experiment demonstrated that the attentional control setting uses an inclusive rule so that cues that share features with targets capture attention even if the cues contain task-irrelevant features. The second experiment extends this finding by examining whether or not the combination cues will produce inhibition of return (IOR) in a modified Folk and Remington paradigm. Posner and Cohen (1984) were the first to show that responses to targets at validly cued peripheral locations become slower when the stimulus onset asynchrony (SOA) between the cues and targets exceeds 300 msec. Since this original finding, IOR has proven to be a very robust phenomenon and has been studied in a wide range of experimental situations (for recent examples, see Abrams $\&$ Pratt, 2000; Briand, Larrison, \& Sereno, 2000; Taylor $\&$ Klein, 2000).

Recently, two studies (Gibson \& Amelio, 2000; Pratt, Sekuler, and McAuliffe, 2001) using the basic Folk and Remington paradigm with much longer SOAs found nearly identical results. First, both studies showed IOR only with the combination of onset cues and onset targets. Second, both studies failed to show IOR when onset cues were paired with color targets, or with color cues and either type of target. Moreover, Gibson and Amelio failed to find IOR when onset cues and "red target alone" targets (similar in style to the combination cues in the present study, a single red discrimination target) were used. Gibson and Amelio explained these findings in terms of what structures of the brain are used to orient attention to the stimuli. They suggested that attentional shifts mediated by midbrain structures (i.e., shifts to abrupt onsets) produce IOR whereas attentional shifts that are more volitional in nature (i.e., shifts to colors) may be mediated by more anterior structures that do not produce IOR.

It was uncertain, however, whether the combination cue used in the previous experiment would or would not elicit IOR in the present experiment. Even if the cue is equally salient on both "onset" and "color" dimensions, the presence of an onset stimuli should activate midbrain structures and generate IOR. Thus, there is reason to suspect that combination cues and onset targets should show IOR. However, Gibson and Amelio (2000) did not find IOR with essentially the reverse order of stimuli: onset cues and "red target only" targets. An alternative possibility is that the long SOA allows the attentional set to be better defined, so that only targets that are very similar to onset cues are inhibited. In other words, the rule used by the attentional control setting may become less inclusive and more exclusive with increasing SOA.

\section{Method}

Participants. Sixteen undergraduate students from the University of Toronto participated in this experiment in return for course credit. Eight participants served in the onset target condition, with the other 8 serving in the color target condition. None of the participants had served in the first experiment.

Apparatus, Procedure, and Design. The experiment used exactly the same apparatus, procedure, and design as the previous experiment except that the delay between the offset of the cue(s) and the onset of the target(s) was increased to $800 \mathrm{msec}$ from $100 \mathrm{msec}$, resulting in a SOA of $850 \mathrm{msec}$ rather than $150 \mathrm{msec}$.

\section{Results and Discussion}

The mean RTs (Figure 3 ) were analyzed with a 2 (group: onset target or color target) $\times 3$ (cue: onset, color, or combination) $\times 2$ (trial type: valid or invalid) ANOVA. There was a main effect of group $[F(1,14)=$ $\left.5.4, M S_{\mathrm{e}}=31,868, p<.04\right]$, again indicating that the discrimination task was easier with the onset targets $(506 \mathrm{msec})$ than with the color targets $(590 \mathrm{msec})$. A main effect was also found for cue $\left[F(2,28)=12.1, M S_{\mathrm{e}}=\right.$ $407, p<.0005]$, with RTs in color cue trials (535 msec) faster than those in onset $(559 \mathrm{msec})$ or combination $(559 \mathrm{msec})$ cue trials. As before, a main effect of trial type was found $\left[F(1,14)=15.0, M S_{\mathrm{e}}=423, p<.002\right]$, with RTs on valid trials $(556 \mathrm{msec})$ slower than RTs on invalid trials $(540 \mathrm{msec})$. Thus, there was an overall IOR effect. As in the previous experiment, the interaction of cue and group with trial type would indicate a differential IOR effect for various cue-target combinations. In this case, the only significant interaction was cue $\times$ trial type $\left[F(2,28)=16.9, M S_{\mathrm{e}}=319, p<.0001\right]$. None of the other interactions approached significance $(F \mathrm{~s}<1)$. As can be seen in Figure 2, the cue $\times$ trial type inter- 


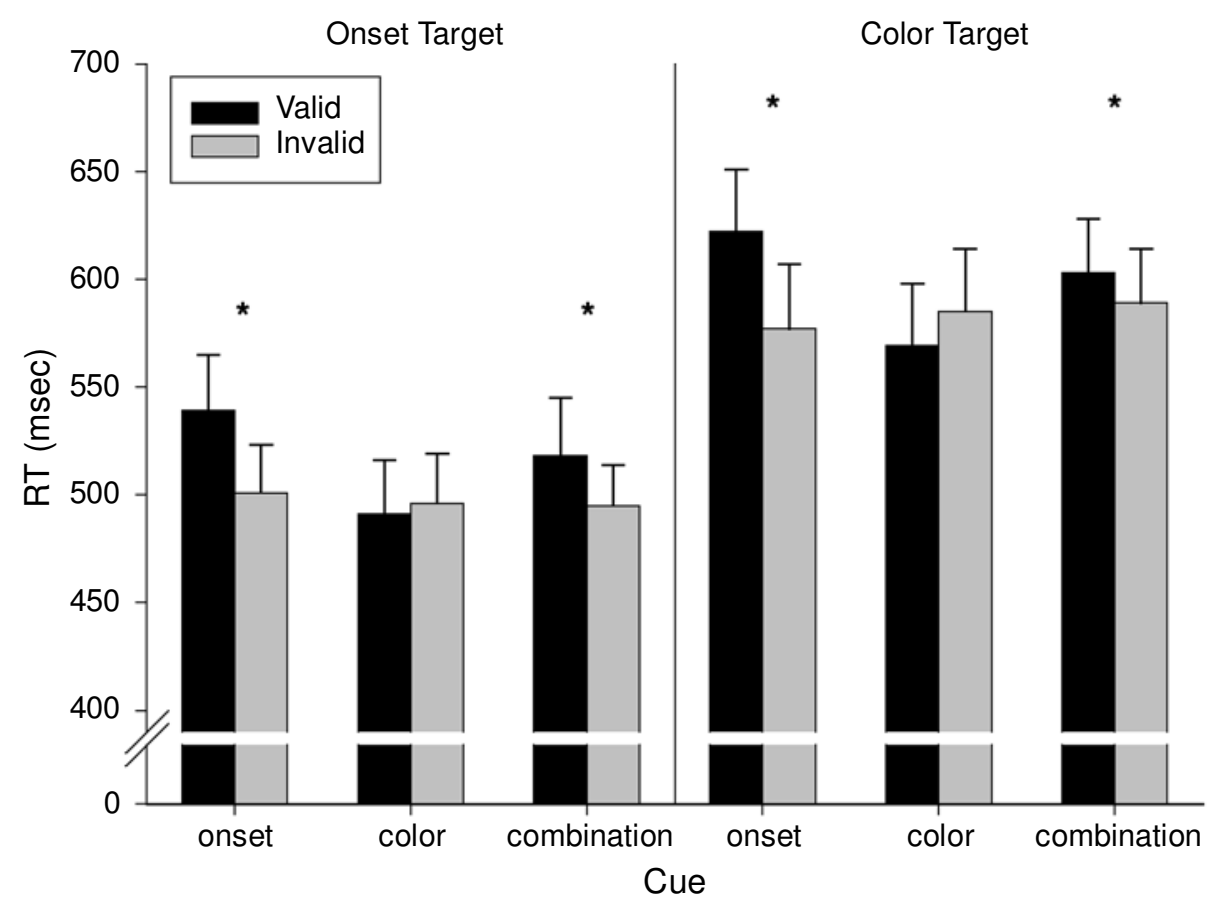

Figure 3. The mean RTs for valid and invalid trials found with the 850 -msec SOA used in Experiment 2 . The asterisks indicate significant effects $(p<.05)$, and error bars represent standard error.

action occurred because IOR occurred for onset and combination cues paired with onset or color targets, whereas IOR did not occur with the color cues or either type of target. Post hoc tests $(p s<.05)$ confirmed that RTs to targets at valid locations were slower than RTs to targets at invalid locations for the following cue-target pairs: onset-onset, combination-onset, onset-color, and combination-color. In other words, the IOR was produced by onset and combination cues regardless of the target type (hence the lack of a group $\times$ trial type interaction).

The percentage of errors (shown in Table 1) was analyzed with a 2 (group) $\times 3$ (cue) $\times 2$ (trial type) ANOVA. No main effects or interaction effects were found $\left(F_{\mathrm{S}}<\right.$ $1.6, p \mathrm{~s}>.22$ ).

Three aspects of these findings are worth noting. First, the finding of IOR in the onset-onset condition and no IOR with the color cues or either target replicates Gibson and Amelio (2000) and Pratt, Sekuler, and McAuliffe (2001). Second, the finding of IOR in the combinationonset condition indicates that the onset feature of the combination cue allowed the combination cue to function much like the typical onset cue. This suggests that the attentional control settings make use of an inclusive rule at longer SOAs. Third, IOR was found with onset and combination cues paired with color targets. As noted earlier, the combination of onset cues and color targets did not produce IOR in either the Gibson and Amelio or the Pratt, Sekuler, and McAuliffe (2001) study. This dis- crepancy in results will be further explored in the following experiment.

\section{EXPERIMENT 3}

An unexpected result from the second experiment was that IOR was found for the onset and combination cues with the color targets. As noted earlier, using essentially the same onset cue and color targets, Gibson and Amelio (2000) and Pratt, Sekuler, and McAuliffe (2001) failed to find IOR. What might account for this difference in results? It might be that the addition of the combination cue altered the attentional control setting in some unforeseen manner. To examine this possibility, the present experiment used only onset and color cues with color targets at a long SOA (replicating the previous conditions used by Pratt, Sekuler, \& McAuliffe). If the presence of the combination cue was the critical feature in finding IOR with the onset cues and color targets in Experiment 2, IOR should not be found in the present experiment.

\section{Method}

Participants. Sixteen undergraduate students from the University of Toronto participated in this experiment in return for course credit. Eight participants served in the random cue condition, with the other 8 serving in the blocked cue condition. None of the participants had served in either of the previous two experiments.

Apparatus, Procedure, and Design. The experiment used the exact same apparatus as the previous experiments. The experimental procedure was the same as that used in Experiment 2 except for 


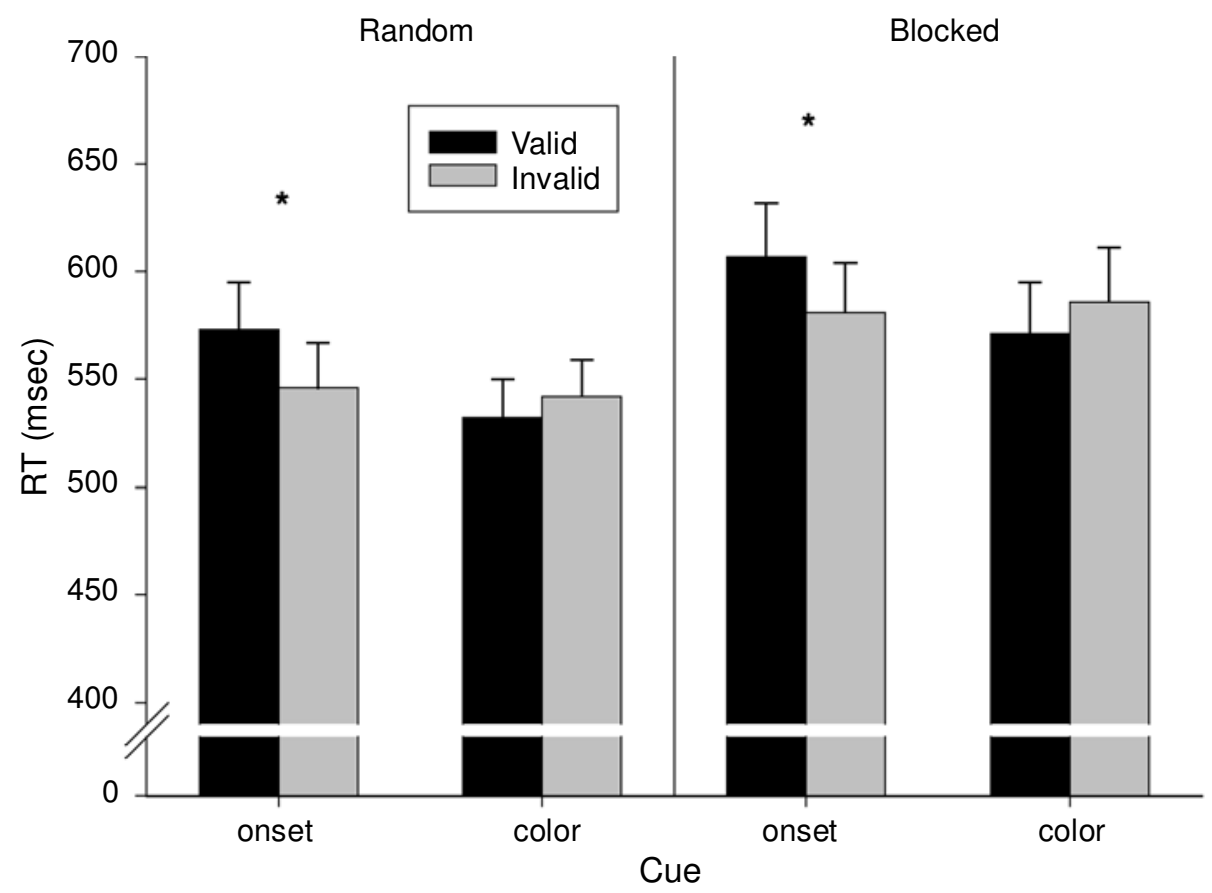

Figure 4. The mean RTs for valid and invalid trials found with the 850-msec SOA used in Experiment 3 (which used only color targets). The asterisks indicate significant effects $(p<.05)$, and error bars represent standard error.

the following differences. First, only onset and color cues, and color targets, were used. Second, the cues were randomly presented to one group of participants (random condition), whereas the cues were blocked for the other group (blocked condition).

Design. There were a total of 384 trials in each session, 192 with the onset cue and 192 with the color cue. As before, the cue and target locations were randomized within each session.

\section{Results and Discussion}

The mean RTs from correct trials (Figure 4) were analyzed with a 2 (group: random or blocked) $\times 2$ (cue: onset or color) $\times 2$ (trial type: valid or invalid) ANOVA. There was a main effect of cue $\left[F(1,14)=6.3, M S_{\mathrm{e}}=\right.$ 956, $p<.03$ ], with faster RTs for color cue trials $(557 \mathrm{msec})$ than for onset cue trials $(576 \mathrm{msec})$. No other main effects were found ( $p$ s $>.14$ ). As before, differential IOR effects for various cue-target combinations would be shown in the interaction effect. As in Experiment 2 , the only significant interaction found was cue $X$ trial type $\left[F(1,14)=17.0, M S_{\mathrm{e}}=371, p<.002\right]$. Group did not interact with either cue or trial type $\left(F_{\mathrm{S}}<1\right)$, and post hoc tests confirmed the presence of IOR for the onset cues and the color targets in both the random and blocked conditions ( $p s<.05)$. As in the previous experiment, onset cues produced IOR for both types of targets, and thus there was no group $\times$ trial type interaction.

The percentage of errors (Table 2) was analyzed with a 2 (cue) $\times 2$ (trial type) ANOVA. No main effects or interaction effects were found $\left(F_{\mathrm{S}}<2.7, p \mathrm{~s}>.17\right)$.

The results from Experiment 3 replicate the finding of IOR for onset cues and color targets reported in Experi- ment 2. As noted before, this finding is inconsistent with Gibson and Amelio (2000) and Pratt, Sekuler, and McAuliffe (2001), and this will be discussed further in the General Discussion section.

\section{GENERAL DISCUSSION}

The major purpose of the present study was to determine whether attentional control settings perform their function by orienting attention to cues that contain taskrelevant features (an inclusive rule) or by not orienting attention to cues that contain task-irrelevant features (an exclusive rule). Experiment 1 yielded the pattern of cuing effects typically associated with contingent involuntary orienting (cuing effects for onset cues with onset targets and color cues with color targets, no cuing effects for onset cues with color targets and color cues with onset targets) as previously reported by Folk and Remington (e.g., Folk et al., 1992; Folk et al., 1994). In addition, cuing effects were found when the cue contained one task-relevant feature and one task-irrelevant feature (a combination cue), indicating that the attentional control

Table 2

Percentage of Errors in Experiment 3, Which Used Only Color Targets

\begin{tabular}{cccccc}
\hline & \multicolumn{2}{c}{ Random } & & \multicolumn{2}{c}{ Blocked } \\
\cline { 2 - 3 } \cline { 5 - 6 } Cue & Valid & Invalid & & Valid & Invalid \\
\hline Onset & 3.0 & 2.6 & & 6.1 & 4.6 \\
Color & 2.6 & 4.5 & & 3.5 & 4.0 \\
\hline
\end{tabular}


settings use an inclusive rule. Experiment 2 indicated that the inclusive rule also applies at long SOAs, since IOR was found when combination cues were presented in either onset or color attentional sets. In addition, this experiment showed IOR for onset cues and onset targets, but not for color cues or either type of target, consistent with earlier work by Gibson and Amelio (2000) and Pratt, Sekuler, and McAuliffe (2001). However, inconsistent with Gibson and Amelio and Pratt, Sekuler, and McAuliffe, IOR was also found with onset cues and color targets. Experiment 3, which used only onset and color cues with color targets to further examine the unexpected finding from the second experiment, confirmed that onset cues and color targets can produce IOR.

The finding of attentional cuing and IOR effects for the combination cues indicates that the attentional control setting uses an inclusive rule. In other words, attention will be allocated to stimuli that have a task-relevant feature. Indeed, there are reasons to think that an inclusive rule might have ecological advantages over an exclusive rule. After all, it is probably better to attend to a stimulus and find out that it is not the target than to not attend to a stimulus and later find out it was the target. In the first case, the search would continue for the target, but in the second case the search might be terminated even though a target was present. Presumably, sharing one task-relevant feature with the target is sufficient to place the stimulus in the attentional set. On the one hand, it is worth noting that the present study, like the basic paradigm of Folk and Remington, used only a limited number of distinguishing features (red or white; single onset or multiple onsets), and it may be possible that target sets that vary on many different task-relevant features may use a less "liberal" inclusive rule. On the other hand, this conclusion is consistent with the findings of Friedman-Hill and Wolfe (1995), who found evidence for an inclusive rule with a varied set of stimuli in a visual search task.

The finding that the onset cues with color targets do not show attentional cuing effects but do show IOR is also relevant to the manner in which attentional control settings operate. The notion from Folk and Remington (e.g., Folk et al., 1992; Folk et al., 1994) is that stimuli that do not match the attentional set are not attended to. Thus, the operation of the attentional control setting occurs before the cue stimulus appears. However, Theeuwes, Atchley, and Kramer (2000) recently suggested that the attentional control setting might operate after the appearance of the cue stimulus (for a schematic of how such an attentional control setting might operate, see Figure 5). In this case, the cue captures attention, but the attentional control setting produces a rapid disengagement of attention from the cue when the cue does not match the target. The finding of IOR with the onset cues and color targets suggests that the onset cue may have been attended to, which is consistent with the Theeuwes et al. notion that the effect of attentional control setting occurs after the appearance of a stimulus. As Theeuwes et al. noted, this is not to say that the attentional control setting is formed after the appearance of the stimulus; presumably the setting is created during the start of a block of trials when the task instructions are given and maintained as long as the task (i.e., the type of target) fits the attentional set. Rather, attention is captured by the onset of a salient stimulus, and then the attentional control setting either allows attention to be maintained briefly at that location (resulting in an attentional cuing effect) or quickly disengages attention (resulting in no cuing effect). This provides a parsimonious explanation for the finding of IOR at longer SOAs with cue-target combinations that did not show cuing effects at shorter SOAs.

It should be noted that although the present results indicate that the onset cues were initially attended to regardless of the attentional set, there has also been recent support for the notion that only cues within the control setting are attended to. Folk and Remington (1999) found that when participants were searching for a color target, compatible and incompatible onset cues did not produce compatibility effects, suggesting that they were not attended to. However, the same cues produced robust compatibility effects when participants searched for onset targets. One reason for the disparate results between the present study and that of Folk and Remington is that relatively long lasting IOR effects may be more reliable than very brief cuing effects or compatibility effects (Pratt, Hillis, \& Gold, 2001). On the other hand, there remains an open debate as to whether IOR is due to an attentional mechanism or an oculomotor mechanism (see Klein, 2000, for a recent overview of IOR). Thus, though the present results are consistent with Theeuwes et al.'s (2000) notion that control settings operate via the rapid disengagement of attention, further research will be necessary to determine the mechanism(s) underlying attentional control settings.

The present results also provide information regarding IOR. As noted earlier, the finding of IOR with the onset cues and color targets is inconsistent with Gibson and Amelio (2000) and Pratt, Sekuler, and McAuliffe (2001). However, this result is consistent with findings from IOR experiments that also used (1) onset cues, (2) discrimination targets, and (3) distractors at nontarget locations (e.g., Kingstone \& Pratt, 1999; Lupiáñez \& Milliken, 1999; Lupiáñez, Milliken, Solano, Weaver, \& Tipper, 2001; Pratt \& Abrams, 1999; Pratt, Kingstone, \& Khoe, 1997). To gain more insight into whether onset cues and color targets produce IOR, we reexamined the individual participant data from the onset cue-color target condition in Pratt, Sekuler, and McAuliffe and found that 9 of the 12 participants in the blocked condition did show IOR effects of various magnitudes. However, the other 3 participants showed large attentional cuing effects, which resulted in a small $(\sim 7-\mathrm{msec})$ nonsignificant overall IOR effect. Examining the individual participant data in the present study for the onset cue-color target conditions revealed that IOR was found with 7 of 


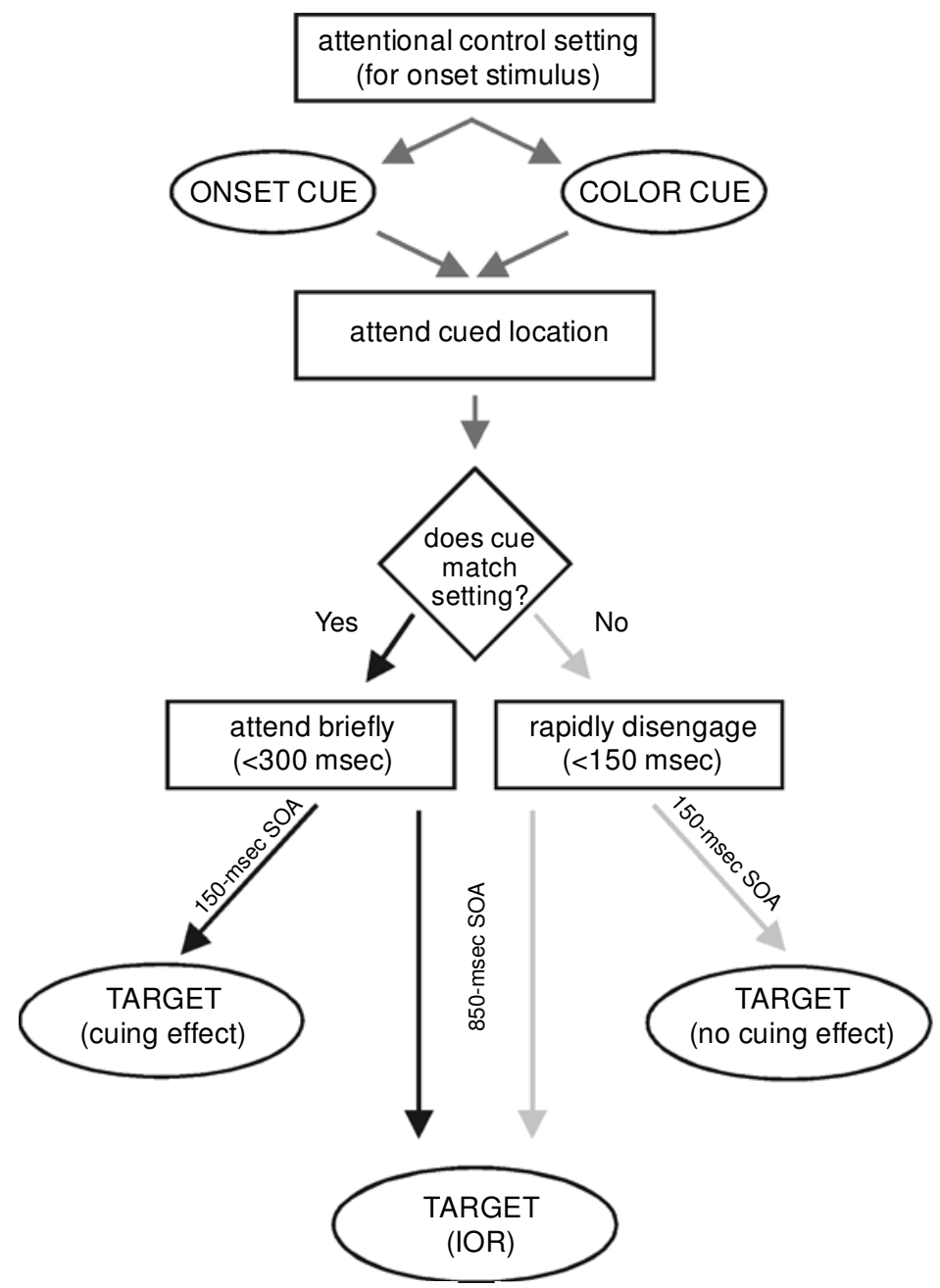

Figure 5. A schematic view of the order of operations in an attentional control setting, as conceived by Theeuwes et al. (2000). See the text for details.

the 8 participants in the long-SOA condition of Experiment 2, and with 15 of the 16 participants in Experiment 3. Moreover, a combined analysis of all 36 participants (combining across the four experiments) showed a significant IOR effect $(p<.018)$. Removing the 3 participants with the large cuing effects from the Pratt, Sekuler, and McAuliffe (2001) study resulted in a significant IOR effect of $p<.004$ for the remaining 32 participants. Thus, despite the Gibson and Amelio results, there is evidence with the Folk and Remington paradigm that IOR at long SOAs can be found in conditions that fail to show attentional cuing effects at short SOAs. This is an important point, since the presence of early attentional cuing effects has been taken by some to be a precondition to the presence of IOR (e.g., Taylor \& Klein, 1998). However, the present findings join a growing list of reports in which IOR has been found in the absence of early attention cuing effects (e.g., Maruff, Yucel, Danckert, Stuart, \& Currie, 1999; Pratt, Hillis, \& Gold, 2001;
Samuel \& Kat, 2002; Tassinari, Agliotti, Chelazzi, Peru, \& Berlucchi, 1994; Tassinari \& Berlucchi, 1993). It seems likely that the peripheral cues produce both a sensory effect (which is inhibitory in nature) and an attentional effect (which is facilitatory in nature), and the specific physical attributes of the cue determine which effect, if either, will predominate at short SOAs. However, the sensory effects are short lived, whereas the attentional effects (i.e., IOR) are relatively long lived, so that in some situations, IOR may be a better indicator of where attention was than attentional cuing effects are an indicator of where attention $i$.

It is worth noting that although the present results are consistent with those found in several IOR studies, it is not immediately obvious why IOR with onset cues and color targets was not found by Gibson and Amelio (2000). There are, however, a few possible reasons. One, and perhaps the most likely, is that Gibson and Amelio used cues that consisted of enlarging and changing the color of the 
placeholder(s) instead of the new objects (dots) that appeared around the placeholders used in the present study (as taken from the typical Folk and Remington contingent orienting paradigm). As Gibson and Amelio noted, the typical dot cues are likely treated as new objects, but their color change cues were likely not treated as such. It is possible that the color change cues simply did not produce sufficient inhibitory effects to be reliably found with the color targets. It is also possible that the individual differences found in Pratt, Sekuler, and McAuliffe (2001) may have been present in the Gibson and Amelio study, who found a nonsignificant $9 \mathrm{msec}$ of inhibition with the onset cues and color targets at the long SOA. Given that their onset cue-onset target condition yielded a modest 19 msec of inhibition, a few extremely "facilitated" participants may have negated the possibility of finding IOR with the onset cues and color targets. Finally, Gibson and Amelio themselves noted that the effects they found with onset cues and color targets should be interpreted with some caution and that the effects of attentional settings in general may be somewhat context dependent.

In summary, the present findings indicate that attentional control settings use an inclusive rule that keeps attention engaged on stimuli that contain a task-relevant feature. Moreover, the results are consistent with the notion that control settings operate after attention has been oriented toward a cued location.

\section{REFERENCES}

Abrams, R. A., \& Pratt, J. (2000). Retinal coding of inhibited eye movements to recently attended locations. Journal of Experimental Psychology: Human Perception \& Performance, 26, 776-788.

Briand, K. A., Larrison, A. L., \& Sereno, A. B. (2000). Inhibition of return in manual and saccadic response systems. Perception \& Psychophysics, 62, 1512-1524.

Folk, C. L., \& Remington, R. W. (1996). When knowledge does not help: Limitations on the flexibility of attentional control. In A. F. Kramer, M. G. H. Coles, \& G. D. Logan (Eds.), Converging operations in the study of visual selective attention (pp. 271-295). Washington, DC: American Psychological Association.

Folk, C. L., \& Remington, R. [W.] (1998). Selectivity in distraction by irrelevant featural singletons: Evidence for two forms of attentional capture. Journal of Experimental Psychology: Human Perception \& Performance, 24, 847-858.

Folk, C. L., \& Remington, R. [W.] (1999). Can new objects override attentional control settings? Perception \& Psychophysics, 61, 727739.

Folk, C. L., Remington, R. W., \& Johnston, J. C. (1992). Involuntary covert orienting is contingent of attentional control settings. Journal of Experimental Psychology: Human Perception \& Performance, 18, 1030-1044.

Folk, C. L., Remington, R. W., \& Wright, J. H. (1994). The structure of attentional control: Contingent attentional capture by apparent motion, abrupt onset, and color. Journal of Experimental Psychology: Human Perception \& Performance, 20, 317-329.

Friedman-Hill, S., \& Wolfe, J. M. (1995). Second-order parallel processing: Visual search for the odd item in a subset. Journal of Experimental Psychology: Human Perception \& Performance, 21, 531-551.

Gibson, B. S., \& Amelio, J. (2000). Inhibition of return and attentional control settings. Perception \& Psychophysics, 62, 496-504.

Kingstone, A., \& Pratt, J. (1999). Inhibition of return is composed of attentional and motor processes. Perception \& Psychophysics, 61, 1046-1054.
KLEIN, R. M. (2000). Inhibition of return. Trends in Cognitive Sciences, 4, 138-147.

LupiáÑEZ, J., \& Milliken, B. (1999). Inhibition of return and the attentional set for integrating versus differentiating information. Journal of General Psychology, 126, 392-418.

Lupiáñez, J., Milliken, B., Solano, C., Weaver, B., \& Tipper, S. P. (2001). On the strategic modulation of the time course of facilitation and inhibition of return. Quarterly Journal of Experimental Psychology, 54A, 753-773.

Maruff, P., Yucel, M., Danckert, J., Stuart, G., \& Currie, J. (1999). Facilitation and inhibition arising from the exogenous orienting of covert attention depends on the temporal properties of spatial cues and targets. Neuropsychologia, 37, 731-744.

Posner, M. I., \& Cohen, Y.(1984). Components of visual orienting. In H. Bouma \& D. G. Bouwhuis (Eds.), Attention \& performance $X$ (pp. 531-556). Hillsdale, NJ: Erlbaum.

Pratt, J., \& ABrams, R. A. (1999). Inhibition of return in discrimination tasks. Journal of Experimental Psychology: Human Perception \& Performance, 25, 229-242.

Pratt, J., Hillis, J., \& Gold, J. M. (2001). The effect of the physical characteristics of cues and targets on facilitation and inhibition. Psychonomic Bulletin \& Review, 8, 489-495.

Pratt, J., Kingstone, A., \& Khoe, W. (1997). Inhibition of return in location- and identity-based choice decision tasks. Perception \& Psychophysics, 59, 964-971.

Pratt, J., Sekuler, A., \& McAuliffe, J. (2001). The role of attentional set on attentional cueing and inhibition of return. Visual Cognition, 8, 33-46.

Remington, R. W., Folk, C. L., \& McLean, J. P. (2001). Contingent attentional capture of delayed allocation of attention? Perception \& Psychophysics, 63, 298-307.

SAmuel, A. G., \& Kat, D. (2002). Inhibition of return: A graphical meta-analysis of its timecourse, and an empirical test of its duration. Manuscript submitted for publication.

Tassinari, G., Agliotti, S., Chelazzi, L., Peru, A., \& Berlucchi, G. (1994). Do peripheral non-informative cues induce early facilitation of target detection? Vision Research, 34, 179-189.

TASSINARI, G., \& Berlucchi, G. (1993). Sensory and attentional components of slowing of manual reaction time to non-fixated visual targets by ipsilateral primes? Vision Research, 33, 1525-1534.

TAYLOR, T. L., \& KLEIN, R. M. (1998). Inhibition of return to color: A replication and nonextension of Law, Pratt, and Abrams (1995). Perception \& Psychophysics, 60, 1452-1456.

TAYLOR, T. L., \& KLEIN, R. M. (2000). Visual and motor effects in inhibition of return. Journal of Experimental Psychology: Human Perception \& Performance, 26, 1639-1656.

Theeuwes, J. (1992). Perceptual selectivity for color and form. Perception \& Psychophysics, 51, 599-606.

Theeuwes, J. (1994). Stimulus-driven capture and attentional set: Selective search for color and visual abrupt onsets. Journal of Experimental Psychology: Human Perception \& Performance, 20, 799-806.

Theeuwes, J., Atchley, P., \& Kramer, A. F. (2000). On the time course of top-down and bottom-up control of visual attention. In S. Monsell \& J. Driver (Eds.), Attention and performance XVIII (pp. 105-124). Cambridge, MA: MIT Press.

Yantis, S., \& Hillstrom, A. P. (1994). Stimulus-driven attentional capture: Evidence from equiluminant visual objects. Journal of Experimental Psychology: Human Perception \& Performance, 20, 95 107.

YANTIS, S., \& Jonides, J. (1984). Abrupt visual onsets and selective attention: Evidence from visual search. Journal of Experimental Psychology: Human Perception \& Performance, 10, 601-621.

YANTIS, S., \& Jonides, J. (1990). Abrupt visual onsets and selective attention: Voluntary versus automatic allocation. Journal of Experimental Psychology: Human Perception \& Performance, 16, 121-134.

(Manuscript received July 23, 2001; revision accepted for publication March 3, 2002.) 